\title{
A case of retinopathy of prematurity treated by pattern scan laser photocoagulation
}

\author{
This article was published in the following Dove Press journal: \\ Clinical Ophthalmology \\ 29 July 2014 \\ Number of times this article has been viewed
}

\section{Satoshi Ota \\ Miho Nozaki \\ Shuichiro Hirahara \\ Tomoaki Hattori \\ Munenori Yoshida \\ Yuichiro Ogura}

Department of Ophthalmology and Visual Science, Nagoya City University Graduate School of Medical Sciences, Nagoya, Japan
Correspondence: Satoshi Ota

Department of Ophthalmology and Visual Science, Nagoya City University Graduate School of Medical Sciences, I-Kawasumi, Mizuho-cho, Mizuho-ku, Nagoya, 467-860I Japan

Tel $+8152853825 I$

Fax +8I 528419490

Email satoshi@med.nagoya-cu.ac.jp
Abstract: We experienced a case of retinopathy of prematurity that was successfully treated with pattern scan laser. Pattern scan laser treatment should be considered as one treatment option for Retinopathy of Prematurity.

Keywords: retinopathy of prematurity, PASCAL, slit-lamp delivery

\section{Introduction}

The Early Treatment for Retinopathy of Prematurity (ETROP) study ${ }^{1}$ demonstrated the effectiveness of laser treatment for the control of retinopathy of prematurity (ROP). Recently, the pattern scan laser system (PASCAL ${ }^{\circledR}$ Streamline; Topcon Medical Laser Systems, Santa Clara, CA, USA) was developed as a new semiautomatic photocoagulator. ${ }^{2}$ With its shorter pulse duration, PASCAL is less time consuming, less painful, and better preserves retinal sensitivity for the patient after laser treatment when compared to conventional laser treatment.,

There are numerous reports that laser photocoagulation use with the PASCAL system is safe and effective for adult retinal vascular diseases, ${ }^{3-6}$ but no reports have been found for ROP. To our knowledge, this is the first case report of ROP that was treated effectively with PASCAL.

\section{Case report}

A male infant was born by caesarean section at 23 weeks of gestation with a birth weight of $564 \mathrm{~g}$. His Apgar score was 1 at 1 minute and 6 at 5 minutes. The first ophthalmic examination was performed at a corrected gestational age of 28 weeks on January 24,2012 . At the first screening examination, we could only identify the optic disc due to a hazy cornea and vitreous opacity in both eyes. At a corrected gestational age of 31 weeks, ROP zone 2, stage 0 was found in both eyes. Because the ROP had gradually progressed to stage 3, zone 2 with disease in his left eye (Figure 1A), we performed laser photocoagulation at a corrected gestational age of 39 weeks (Figure 1B). Informed consent was obtained from the family by a written letter, which was performed in accordance with the tenets of the Declaration of Helsinki after sufficient explanation and discussion. Laser photocoagulation was used for the left eye using PASCAL ${ }^{\circledR}$ Streamline. The conditions of the photocoagulation were: irradiation time, 20-30 ms; laser power, 300-350 mW; spot size, $200 \mu \mathrm{m}$; spacing, $100 \mu \mathrm{m}$; and laser shots, 2,999 shots with a wide-field pediatric contact lens (Quad Pediatric Lens; Volk Optical Inc., Mentor, OH, USA). The infant was subjected to general anesthesia with fentanyl citrate by intravenous injection ( $4 \mu \mathrm{g} / \mathrm{kg} / \mathrm{hour})$.

Two weeks after laser photocoagulation, fibrovascular proliferation began to regress with scarring of the laser photocoagulation spots. The expansion of the vein 
A

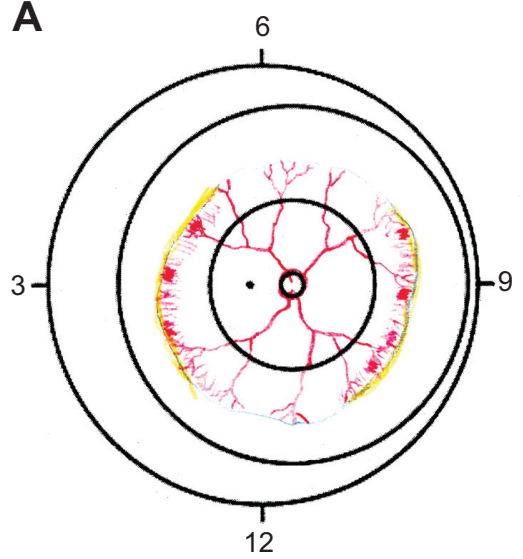

B

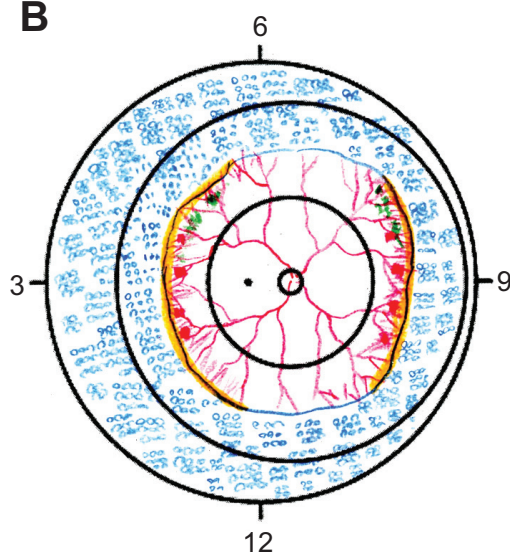

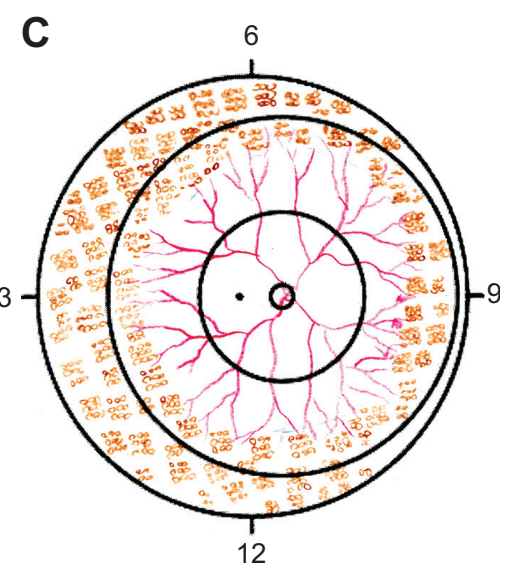

Figure I Fundus sketches of the left eye obtained by indirect ophthalmoscope.

Notes: (A) At 16 weeks of corrected gestational age, before laser treatment. (B) Just after the laser treatment. (C) Eight weeks after laser photocoagulation.

and fibrovascular proliferation almost disappeared 5 weeks later, and the D-line diminished 8 weeks later (Figures 1C and 2). Despite a fair ophthalmological prognosis, the patient died because of pulmonary hypertension due to chronic lung disease and tension pneumothorax at a corrected gestational age of 3 months.

\section{Discussion}

ROP is a blood vessel disease characterized by increased fibrovascular proliferation, which primarily develops in children with a birth weight $<1,500 \mathrm{~g} .{ }^{1}$ In recent years, the survival rate of low birth weight children has improved due

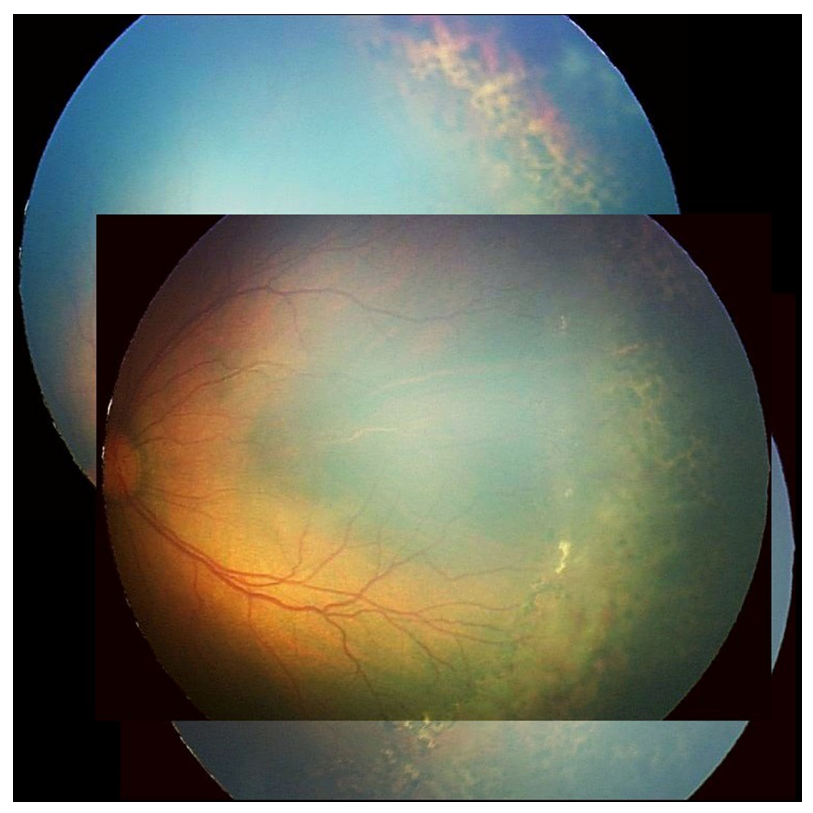

Figure 2 Fundus photograph taken 8 weeks after pattern scan laser system PASCAL ${ }^{\circledR}$ Streamline (Topcon Medical Laser Systems, Santa Clara, CA, USA) laser photocoagulation.

Note: Latticed pattern of laser scars is noted. to progress in newborn baby medical care and, accordingly, severe ROP has increased. ${ }^{1}$

In addition to cryotherapy, laser photocoagulation is one of the treatments for ROP. Compared with cryotherapy, which may cause several ocular-related adverse events including conjunctival laceration, vitreous hemorrhage, and a constricted visual field, ${ }^{7,8}$ laser photocoagulation is popular because it has fewer complications and is as effective as cryotherapy. ${ }^{9}$

In this report, we describe a case of ROP that was successfully treated by PASCAL through a wide-field pediatric contact lens. It was reported that slit-lamp argon laser photocoagulation for ROP through the Quad Pediatric Lens was efficient and precise, associated with a lower rate of complications, and it was effective with binocular indirect ophthalmoscopy. ${ }^{10}$ However, to our knowledge, a case of ROP treated using PASCAL has not been reported.

PASCAL is a semiautomatic pattern scan laser that is used in a predetermined sequence for retina photocoagulation. ${ }^{2}$ When compared with conventional photocoagulation, photocoagulation with PASCAL has some features that could be beneficial for the treatment of ROP. It takes a shorter amount of time for the treatment to be completed, it causes less damage to the inner layer of the retina, ${ }^{4,11}$ and it causes less pain to the patient. ${ }^{12}$

In our facility, we usually use an argon green laser with an indirect ophthalmoscope delivery system (Nidek Co., Ltd., Gamagori, Aichi, Japan $)^{13}$ to treat ROP, and it takes about 40 minutes to set up, and 40 minutes to conduct the laser photocoagulation procedure itself. In our experience with PASCAL, the procedure took about 40 minutes to set up because we had to remove the chinrest stand to fix the infant with an endotracheal tube in a lateral decubitus position to 


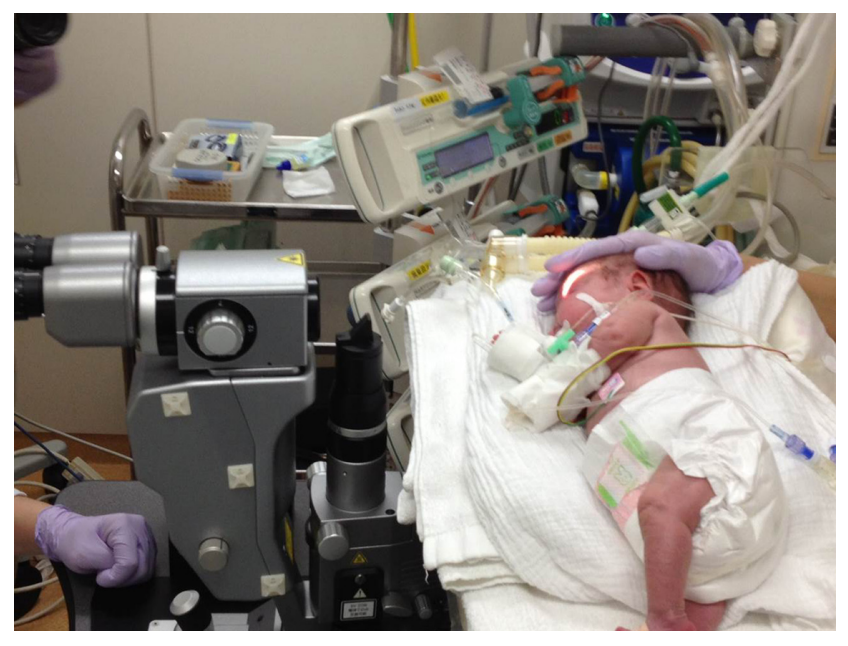

Figure 3 Removal of the chinrest to fix the patient with an incubator tube in a lateral decubitus position.

deliver the laser photocoagulation via a table-mounted slit lamp (Figure 3). Furthermore, the laser photocoagulation procedure time amounted to about 40 minutes, which was almost the same as with a conventional laser. However, this was our first case where we treated ROP by PASCAL, and it took extra time to set up and position the system during laser photocoagulation. Thus, we estimate that the procedure time can be reduced by up to $50 \%$ when compared to conventional laser once we encounter more ROP cases.

There are two points that are important in this setting. One is that the heights of the slit-lamp table and the infant's bed should almost be the same. The other is that the distance from the patient's eye to the slit lamp should not be too large. The comma-shaped design of the PASCAL slit-lamp table was not so desirable to fit to our infant's bed, and that was why the setup required a longer time in our case. If the table were rectangular, the setup would be easier and faster. This modality could also be feasible for patients needing positivepressure mask ventilation or a nasal cannula.

It has been reported that PASCAL requires a greater number of laser pulses to obtain an equal effect when compared to conventional laser treatments for proliferative diabetic retinopathy. ${ }^{14}$ Although conventional retinal photocoagulation causes progressive expansion of laser scars over a long period, ${ }^{15}$ pattern scan laser treatments with a shorter pulse duration can cause less expansion in scar size, ${ }^{11,14,16}$ and it requires almost double spots in order to maintain the same total coagulation area. ${ }^{16}$ In our facility, we usually use an argon green laser with an indirect ophthalmoscope delivery system to treat ROP. The conditions of the photocoagulation are: irradiation time, 0.2 seconds; laser power, $120 \mathrm{~mW}$; spot size, $200 \mu \mathrm{m}$; and a distance of 1-1.5 spots apart. The number of spots is about 2,000 with these photocoagulation conditions.

Compared with conventional laser treatment with 1-1.5 spacing, we produced 2,999 laser spots with 0.5 spacing with PASCAL. One week after the laser photocoagulation procedure, we confirmed the regression of proliferation, and we determined that PASCAL laser photocoagulation with spacing at 0.5 could be adequate for ROP treatment.

From many experiences with adult patients, we believe that pattern scan laser with a higher number of laser spots would be sufficient in achieving regression of vascular proliferation, but for ROP, we do not know the long-term effects of the higher number of laser spots during treatment. The benefits of this procedure would include shorter procedure times and less pain. Despite the fact that the patient was under general anesthesia, we speculate that the patient might be more comfortable after laser photocoagulation when compared to conventional laser. We had explained these possible benefits and risks to the family and had obtained their written consent.

The patient's ophthalmologic prognosis was fair at 2 months after PASCAL photocoagulation, but the patient had chronic lung disease with progressive pulmonary hypertension. He subsequently developed pneumonia and died of tension pneumothorax. In our facility, reintubation occurs in all patients who are under general anesthesia when we perform laser photocoagulation for ROP, so as to conduct the laser therapy safely. In this case, we did not experience any vital changes during laser photocoagulation, and no relation was confirmed between PASCAL laser photocoagulation and death.

\section{Conclusion}

In conclusion, we reported a case of ROP that was successfully treated with pattern scan laser. Unfortunately, we could not obtain longer-term outcomes for this patient, but we suppose that pattern scan laser for ROP is beneficial because the long-term prognosis of laser photocoagulation in ROP is generally pretty fair if the neovascularization regresses. Despite the short follow-up period, we confirmed the regression of neovascularization after PASCAL laser photocoagulation, so that PASCAL laser photocoagulation could be thought of as one treatment option for ROP.

A larger randomized clinical study is required to verify the extent, and the long-term safety and efficacy, of this treatment in ROP. However, from our experience, pattern scan laser treatment should be considered as one treatment option for ROP because it provides a shorter treatment time and less pain than conventional laser treatment. 


\section{Disclosure}

The authors report no conflicts of interest in this work.

\section{References}

1. Good WV, Hardy RJ, Dobson V, et al; Early Treatment for Retinopathy of Prematurity Cooperative Group. The incidence and course of retinopathy of prematurity: findings from the early treatment for retinopathy of prematurity study. Pediatrics. 2005;116(1):15-23.

2. Blumenkranz MS, Yellachich D, Andersen DE, et al. Semiautomated patterned scanning laser for retinal photocoagulation. Retina. 2006; 26(3):370-376.

3. Nagpal M, Marlecha S, Nagpal K. Comparison of laser photocoagulation for diabetic retinopathy using 532-nm standard laser versus multispot pattern scan laser. Retina. 2010;30(3):452-458.

4. Muqit MM, Marcellino GR, Henson DB, Fenerty CH, Stanga PE. Randomized clinical trial to evaluate the effects of Pascal panretinal photocoagulation on macular nerve fiber layer: Manchester Pascal Study report 3. Retina. 2011;31(8):1699-1707.

5. Velez-Montoya R, Guerrero-Naranjo JL, Gonzalez-Mijares CC, et al. Pattern scan laser photocoagulation: safety and complications, experience after 1301 consecutive cases. Br J Ophthalmol. 2010;94(6): 720-724.

6. Muqit MM, Sanghvi C, McLauchlan R, et al. Study of clinical applications and safety for Pascal ${ }^{\circledR}$ laser photocoagulation in retinal vascular disorders. Acta Ophthalmol. 2012;90(2):155-161.

7. Multicenter trial of cryotherapy for retinopathy of prematurity. Preliminary results. Cryotherapy for Retinopathy of Prematurity Cooperative Group. Arch Ophthalmol. 1988;106(4):471-479.
8. Quinn GE, Miller DL, Evans JA, Tasman WE, McNamara JA, Schaffer DB. Measurement of Goldmann visual fields in older children who received cryotherapy as infants for threshold retinopathy of prematurity. Arch Ophthalmol. 1996;114(4):425-428.

9. Pearce IA, Pennie FC, Gannon LM, Weindling AM, Clark DI. Three year visual outcome for treated stage 3 retinopathy of prematurity: cryotherapy versus laser. Br J Ophthalmol. 1998;82(11):1254-1259.

10. Urrets-Zavalia J, Urrets-Zavalia E, Iros M. [Slit-lamp laser photocoagulation with a quadraspheric contact lens for the treatment of retinopathy of prematurity]. J Fr Ophtalmol. 2000;23(4):361-363. French.

11. Jain A, Blumenkranz MS, Paulus Y, et al. Effect of pulse duration on size and character of the lesion in retinal photocoagulation. Arch Ophthalmol. 2008;126(1):78-85.

12. Mugit MM, Marcellino GR, Gray JC, et al. Pain responses of Pascal $20 \mathrm{~ms}$ multi-spot and $100 \mathrm{~ms}$ single-spot panretinal photocoagulation: Manchester Pascal Study, MAPASS report 2. Br J Ophthalmol. 2010;94(11):1493-1498.

13. Ikeda $\mathrm{H}$, Kuriyama S. Risk factors for retinopathy of prematurity requiring photocoagulation. Jpn J Ophthalmol. 2004;48(1):68-71.

14. Muqit MM, Marcellino GR, Henson DB, Young LB, Turner GS, Stanga PE. Pascal panretinal laser ablation and regression analysis in proliferative diabetic retinopathy: Manchester Pascal Study Report 4. Eye (Lond). 2011;25(11):1447-1456.

15. Maeshima K, Utsugi-Sutoh N, Otani T, Kishi S. Progressive enlargement of scattered photocoagulation scars in diabetic retinopathy. Retina. 2004;24(4):507-511.

16. Palanker D, Lavinsky D, Blumenkranz MS, Marcellino G. The impact of pulse duration and burn grade on size of retinal photocoagulation lesion: implications for pattern density. Retina. 2011;31(8):1664-1669.

\section{Clinical Ophthalmology}

\section{Publish your work in this journal}

Clinical Ophthalmology is an international, peer-reviewed journal covering all subspecialties within ophthalmology. Key topics include: Optometry; Visual science; Pharmacology and drug therapy in eye diseases; Basic Sciences; Primary and Secondary eye care; Patient Safety and Quality of Care Improvements. This journal is indexed on Submit your manuscript here: http://www.dovepress.com/clinical-ophthalmology-journal

\section{Dovepress}

PubMed Central and CAS, and is the official journal of The Society of Clinical Ophthalmology (SCO). The manuscript management system is completely online and includes a very quick and fair peer-review system, which is all easy to use. Visit http://www.dovepress.com/ testimonials.php to read real quotes from published authors. 